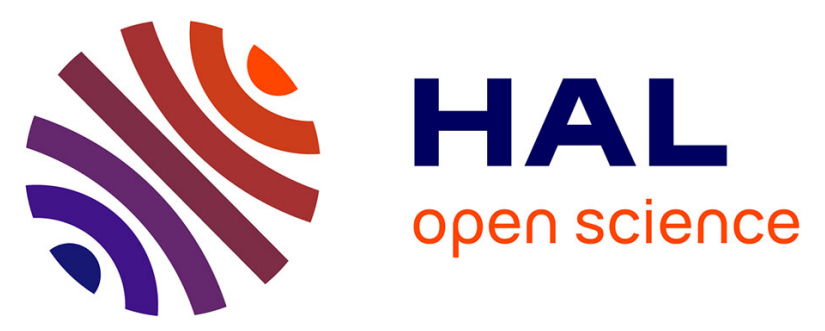

\title{
Friend or foe: Reconciliation between males and females in wild chacma baboons
}

\author{
Christine E Webb, Alice Baniel, Guy Cowlishaw, Elise Huchard
}

\section{To cite this version:}

Christine E Webb, Alice Baniel, Guy Cowlishaw, Elise Huchard. Friend or foe: Reconciliation between males and females in wild chacma baboons. Animal Behaviour, 2019, 151, pp.145-155. 10.1016/j.anbehav.2019.03.016 . hal-02114573

\section{HAL Id: hal-02114573 \\ https://hal.science/hal-02114573}

Submitted on 29 Apr 2019

HAL is a multi-disciplinary open access archive for the deposit and dissemination of scientific research documents, whether they are published or not. The documents may come from teaching and research institutions in France or abroad, or from public or private research centers.
L'archive ouverte pluridisciplinaire $\mathbf{H A L}$, est destinée au dépôt et à la diffusion de documents scientifiques de niveau recherche, publiés ou non, émanant des établissements d'enseignement et de recherche français ou étrangers, des laboratoires publics ou privés. 
1 Friend or foe: Reconciliation between males and females in wild chacma baboons

2

4

$5 \quad{ }^{1}$ Department of Human Evolutionary Biology, Harvard University, Cambridge MA, USA

$6 \quad{ }^{2}$ Institute for Advanced Study in Toulouse, Toulouse, France

$7 \quad{ }^{3}$ Institute of Zoology, Zoological Society of London, London, UK

$8{ }^{4}$ Institute of Evolutionary Biology of Montpellier (ISEM), Université de Montpellier, CNRS,

9 Montpellier, France

10

11

* Joint first authors

12

Declarations of interest: none

13

17 Word count: 6,190

18

Correspondence: C. E. Webb, Department of Human Evolutionary Biology, Harvard

University, 11 Divinity Ave, Cambridge, MA 02138 USA

24

E-mail address: cwebb218@gmail.com

25

Phone: +1 3023791390 


\section{Abstract}

2 Male aggression towards females is a common and often costly occurrence in species that live in bisexual groups. But preferential heterosexual relationships are also known to confer numerous fitness advantages to both sexes-making it of interest to explore how aggression is managed among male-female dyads through strategies like reconciliation (i.e., post-conflict affiliative reunions between former opponents). In this study, we build on traditional PC-MC, time-rule, and rate methods to validate a novel methodological approach that tests for the presence and form of reconciliation between male and female wild chacma baboons (Papio ursinus). We show that heterosexual opponents exhibit friendly post-conflict reunions, further demonstrating that reconciliation occurs almost exclusively between males and pregnant/lactating females who form tight social bonds. Such 'friendships' represent stable associations offering proximate and ultimate benefits to both parties-mainly improving (future) offspring survival. This aligns our findings with the Valuable Relationship Hypothesis, which predicts rates of reconciliation to increase with the fitness consequences of the opponents' bond. Moreover, patterns concerning the initiative to reconcile reveal that males are as likely as females to initiate reconciliation, suggesting that males play a heretofore underappreciated role in maintaining heterosexual friendships. Beyond proposing a multivariate methodological technique applicable to other long-term observational datasets, the present research illuminates how male-female aggression in promiscuous societies may be mitigated via relationship-repair strategies like reconciliation, the balance in those efforts between partners shedding new light on the mutual investment in such bonds.

Keywords: Reconciliation, post-conflict affiliation, aggression, male-female association, chacma baboons 
Conflict is an inherent yet often detrimental consequence of group living in animals. Its potential fitness costs include injury, stress, resource loss, and perhaps above all—irreparable damage to social relationships. It is therefore of great interest to understand the mechanisms by which animals manage and mitigate conflict. One such strategy is reconciliation, or friendly reunions between former opponents occurring soon after conflicts (de Waal \& van Roosmalen, 1979). Since its inception, research in this area has sought to identify the factors that predict variation in reconciliation's occurrence. Paramount among these factors is the nature of the relationship between opponents (de Waal \& Aureli, 1997). Approaching a recent conflict opponent entails a certain risk, and thus partners should reconcile when they stand more to lose if they do not repair their damaged bond. Accordingly, the Valuable Relationship Hypothesis (VRH) posits that reconciliation should occur whenever the quality of the relationship has important fitness consequences for the opponents (de Waal \& Aureli, 1997; Kappeler \& van Schaik, 1992). This hypothesis generates key insights to animal sociality at different levels of analysis.

At one level, tests of the VRH have shed light on how social relationships vary across different types of social organization. This is exemplified by studies assessing rates of reconciliation between and within sexes. For example, conciliatory tendencies are highest between females in female-bonded macaque societies where matrilineal kin play an important role in rank acquisition and maintenance (Cooper, Bernstein, \& Hemelrijk, 2005; Schino, Rosati, \& Aureli, 1998). On the contrary, in chimpanzees, strong male intrasexual alliances due to male philopatry are thought to promote higher reconciliation rates between male opponents (de Waal, 1986; Koski, Koops, \& Sterck, 2007; Watts, 2006; cf Fraser, Stahl, \& Aureli, 2010). In mountain gorillas and hamadryas baboons, females often reconcile with the adult male of their social unit, who commonly provides protection and agonistic support 
51 (Romero, Colmenares, \& Aureli, 2008; Watts, 1995). As this brief overview illustrates, the vast majority of reconciliation research has focused on primates (see Romero \& Aureli, 2007, Table 1). Though limited by comparison, systematic studies of reconciliation in non-primate animal societies, including canids (Cools, Van Hout, \& Nelissen, 2008; Cordoni \& Palagi, 2008), cetaceans (Weaver, 2003), marsupials (Cordoni \& Norscia, 2014), hyenas (Wahaj, Guse, \& Holekamp, 2001), domestic horses (Cozzi, Sighieri, Gazzano, Nicol, \& Baragli, 2010) and goats (Schino, 1998), corvids (Fraser \& Bugnyar, 2011), and fish (Bshary \& Würth, 2001) have revealed that post-conflict affiliative behaviours are by no means limited to primate or even mammalian taxa, and have provided new insights to the VHR. For example, reconciliation is thought to be largely absent in cooperative breeders because valuable partners (i.e., the breeding pair) rarely engage in aggression (Logan, Emery, \& Clayton, 2012; Seed, Clayton, \& Emery, 2007). Further, in the only evidence to date of interspecies reconciliation, cleaner wrasse fish reconcile with their valuable client reef partners, underscoring the fundamental role such relationships play in this symbiotic dynamic (Bshary \& Würth, 2001). By and large, this work highlights how patterns of reconciliation reflect and underpin animal social structure.

At another level, tests of the VRH have been instrumental in revealing the nature of individualized relationships within animal social groups. For instance, Wittig and Boesch (2003) found that chimpanzee dyads who support one another and share food reconcile more often than those who do not. Likewise, coalitionary support predicts post-conflict affiliation in wolves (Cordoni \& Palagi, 2008), whereas familiarity may facilitate reconciliation in dogs (Cools et al., 2008). In a number of primate species, dyads characterized by more frequent affiliation-e.g., as indexed by grooming and proximity measures—are known to exhibit higher conciliatory tendencies than less affiliative dyads (reviewed in Romero \& Aureli 2017). Similarly, Fraser and Bugnyar (2011) found that reconciliation in pairs of ravens is positively related to durations of allopreening and contact-sitting (measures that further relate to agonistic 
support). In the only experimental test of the VRH to date, pairs of long-tailed macaques were trained to cooperate in order to obtain food rewards. Reconciliation was three times more likely to occur (relative to baseline rates) in those dyads whose relationships had been artificially enhanced (Cords \& Thurnheer, 1993). Through such direct measures and manipulations of relationship value, tests of the VRH highlight which social bonds are most worthy of repair following disruption by conflict.

A basic tenet of studies on reconciliation is that interaction patterns in post-conflict periods differ in a meaningful way from interaction patterns at other times. To achieve this, researchers have employed various methodologies, each with its own advantages and shortcomings (reviewed in Kappeler \& van Schaik 1992; Cords 1993; Veenema et al. 1994). By far the most common approach is the 'PC-MC method' (de Waal \& Yoshihara, 1983), wherein the timing of the first affiliative interaction between former opponents during a postconflict (PC) sample is compared with that of a corresponding matched-control (MC), usually sampled within one week of the conflict. One advantage of comparing a particular PC reunion to a single control observation matched within this temporal window is that it accounts for potential fluctuations in dyad members' social bond over time. At the same time, this method can generate noisy data, as stochasticity in the selection of a single MC observation means that it may not be representative of the baseline affiliation characterizing a given dyad (Cords, 1993). This problem is partially circumvented by methodologies that compare PCs to a wider subset of control observations, such as the 'time-rule method,' wherein the frequency distribution of the first affiliative interaction as a function of time in aggregate PCs is compared with the equivalent distribution in aggregate MCs (see Aureli, van Schaik, \& van Hooff, 1989), or the 'rate method,' which compares the distribution of the mean rate of affiliation in PCs and MCs (see Judge, 1991). However, because these observations are not time-matched, such methods may be less robust if there are temporal fluctuations in social relationships over the 
same period. Nonetheless, researchers have advocated for the use of baseline levels of interaction over traditional PC-MC approaches for a variety of reasons (e.g., Aureli et al., 1989; Cords, 1993; Kappeler \& van Schaik, 1992; Veenema et al., 1994). Although these methods typically yield complementary findings (Kappeler \& van Schaik, 1992), they occasionally lead to discrepant results (e.g., Kappeler 1993). At present, a combination of approaches is therefore considered the most reliable way to test for reconciliation’s presence (Veenema, 2000).

In the current research, we apply—and build on —-these methods to validate a novel methodological approach in our study system, a population of wild chacma baboons. To date the vast majority of research on reconciliation has been conducted on captive primate groups (reviewed in Arnold et al. 2010), although studies are increasingly carried out in naturalistic settings. This bias likely stems in part from practical limitations associated with collecting proper PC-MC data in non-captive/controlled settings. It may also reflect putative analytical constraints on long-term data that were not explicitly collected to study reconciliation, wherein rather strict adherence to the conventional PC-MC protocol has persisted despite the emergence We apply this methodology to test the VRH in an original and meaningful context- 
in friendly post-conflict reunions. Thus far most research on the fitness benefits of animal social

127 bonds have focused on same-sex relationships (e.g., McDonald 2007; Yee et al. 2008; Silk et al. 2010; Stanton \& Mann 2012), but relationships between males and females also have a documented impact on individual fitness (Archie, Tung, Clark, Altmann, \& Alberts, 2014; Cheney, Silk, \& Seyfarth, 2012). Research on reconciliation in chacma baboons to date may reflect this imbalance, focusing exclusively on post-conflict behaviour amongst adult female opponents (e.g., Cheney et al. 1995; Silk et al. 1996; Wittig et al. 2007). It is therefore of interest to investigate whether heterosexual opponent dyads also reconcile, particularly given the high frequency of male aggression towards females in this species (Baniel, Cowlishaw, \& Huchard, 2017). The presence of reconciliation between males and females would further elucidate the nature and value of adult heterosexual bonds in promiscuous societies, including how those bonds are sustained despite conflict being a common occurrence.

On another level, we were interested in applying the VRH to test differentiated relationships within these heterosexual dyads. Namely, chacma baboons live in large multimale-multifemale societies where females are philopatric and dispersing males compete for reproductive opportunities. It is common for pregnant and lactating females to associate with the father of their offspring, and such 'friendships' may enhance the fitness of both partners via paternal care (Baniel, Cowlishaw, \& Huchard, 2016; Huchard et al., 2010, 2013; affiliation at higher rates than expected from baseline affiliative patterns, thereby providing evidence for reconciliation; (2) the occurrence of reconciliation would be more frequent between male-female friends than non-friends, as the former should be motivated to maintain 
mutual fitness benefits that might otherwise be disrupted by conflict; and (3) females would initiate reconciliations more frequently than their male friends, as spatial proximity between friends appears to be almost exclusively maintained by females (Huchard et al., 2010; Palombit, Cheney, \& Seyfarth, 2001; Palombit et al., 1997), who therefore seem to play the primary role in sustaining these mutually beneficial bonds.

\section{MATERIAL \& METHODS}

\section{(a) Data collection}

Data were collected in 2005-06 and 2013-14 from two habituated groups of wild chacma baboons living at Tsaobis Nature Park (2202'S $\left.15^{\circ} 44^{\prime} \mathrm{E}\right)$, Namibia (for details of the site and population, see (Cowlishaw, 1997)). Group composition and study periods are given in Table S1. Males were considered adult when they reached eight years of age (Alberts \& Altmann, 1995) and females when they reached menarche (Altmann \& Alberts, 2003). Dominance ranks of adult males and females were established using both ad libitum and focal observations of dyadic agonistic interactions (see Appendix 1 in Supplementary Materials). The reproductive state of each female was monitored daily and categorised as follows: (1) pregnant, where pregnancy was determined post hoc following infant birth, and encompassed the six months since the conceptive cycle; (2) lactation, if she had a dependant infant and had not yet resumed cycling, (3) cycling oestrous, if she was sexually receptive with a perineal swelling, and (4) cycling non-oestrous otherwise.

Observers on foot followed groups daily from dawn to dusk, conducting 1-hour focal observations (mean duration \pm SD: $59.9 \pm 3.6 \mathrm{~min}$ ) on all adult females and males (male observations were only collected in 2013-14), spread equally across the day. In total, we collected 3541 focal observations on 54 females (mean \pm SD: $65.6 \pm 45.5$ observations per

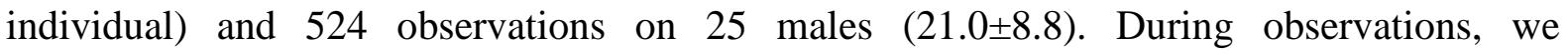


continuously recorded all occurrences of male-female agonistic and affiliative interactions involving the focal individual, noting the partner's identity and the direction of the interaction. Agonistic interactions comprised attacks (any aggressive physical contact including bites, hits, grabbing), chases, and threats (including staring, head bobbing, and ground sweeping while oriented toward the targeted individual). As expected on the basis of pronounced sexual dimorphism, 97\% of conflicts were directed from males to females (351/361 conflicts). Affiliative interactions included grunts, positive facial expressions (come-here faces, lipsmacks, sniff-mouths), positive physical contacts (touching, embracing, grooming, touching perineum, mounting, grasping pelvis), and socio-sexual interactions (presenting hindquarters to another individual across sexual and nonsexual contexts, copulating). Greetings frequently involved a sequence of several affiliative interactions in short succession, so affiliative interactions occurring within 30 seconds of each other in the same dyad were considered as non-independent and we only retained the first interaction to avoid pseudoreplication. We also monitored approaches and leaves continuously within one meter between the focal individual and other adults of the group to establish the time spent in close proximity. Finally, we conducted proximity scans every five minutes to record the identity and distance of the nearest adult male (in the case of female observations) or female (in the case of male observations) neighbour.

\section{(b) Identification of heterosexual friendships}

The male friend(s) of each pregnant and lactating female (i.e., the male(s) with whom they had a particularly strong social bond) was identified using a combination of spatial proximity and grooming allocation indices, following an established method (Baniel et al., 2016). Note that cycling oestrous and non-oestrous females usually do not form such long-lasting friendships with males. First, we calculated dyadic proximity and grooming scores between all pregnant 
or lactating females and resident males. The grooming allocation index was calculated as the number of grooming bouts that a female gave to a male divided by the total number of grooming bouts given by that female to any male of the group. The dyadic spatial proximity index was calculated as the number of scans in which the male was the female's nearest neighbour divided by the total number of scans collected for that female. Second, for each behavioural index we investigated if one or two males had an outstandingly high score compared to other males, hereafter referred as the "preferred male(s).” We ranked males from the highest to the lowest score, then calculated the ratio of the highest index divided by the second highest index, and the ratio of the second highest index divided by the third highest index. If the first ratio was higher than two (i.e., the male with the highest index had twice as many interactions with the female than the second male), we assigned only one preferred male — the one with the highest score — to the female. If the second ratio was also higher than two, we assigned two preferred males — the ones with the first and second highest indices—-to the female. If no male had a highly differentiated score compared to the others, we considered the female to have no preferred male for this reproductive state. Thus, pregnant/lactating females could have one, two, or no preferred male(s). Third, we compared the preferred male(s) designated by each behavioural index and considered as "male friend" the male that was preferred according to both grooming and proximity indices. Using this criterion, a female would have either one or two male friend(s) or, in the case of undifferentiated relationships with males, no friend. Friendship assignment was conducted separately for lactating females risk decreases considerably after this age (Palombit et al., 1997) and mothers show weaker associations with their male friend and/or occasionally terminate associations (by switching male partners) after this critical period (Baniel et al., 2016). Overall, we identified at least one male friend for $83 \%$ of pregnant and lactating females. 


\section{(c) Statistical Analyses}

\section{Validating a novel method to study reconciliation}

We tested for patterns of reconciliation between former male and female opponents by implementing two complementary methods: (1) the post-conflict matched-control ('PC-MC') method (de Waal \& Yoshihara, 1983; Veenema, 2000), which has so far been the conventional approach to establish the occurrence of reconciliation in animals, and (2) a new method which builds on the time-rule and rate methods (Aureli et al., 1989; Cords, 1993; Judge, 1991; Kappeler \& van Schaik, 1992; Veenema et al., 1994), which have been less widely used but are more practical for long-term observational datasets from wild populations that were not explicitly collected to analyze reconciliation patterns (Kutsukake \& Castles, 2004; Silk et al., 1996; Wittig \& Boesch, 2003). As a first step, we thus aimed to validate this new method using a large sample of conflicts from our study system, ensuring that results corresponded with those generated by a more traditional PC-MC approach.

\section{Post-conflict matched-control method}

We used an extended matched-control analysis (de Waal \& Yoshihara, 1983) to test whether individuals were more likely to affiliate with a former opponent within 5-20 minutes after a conflict. After each instance of intersexual aggression (chase, attack or threat), we selected the $x(x=5,10,15$ and 20$)$ following minutes of the focal observation, hereafter called the postconflict ('PC') observation, and assessed whether at least one affiliation occurred with the opponent (no: 0 ; yes: 1). When it occurred, we also recorded the timing, type and direction of the first affiliation. When another conflict happened within $\mathrm{x}$ minutes of the first conflict, we excluded the first PC observation from the dataset, and only retained the $\mathrm{x}$ minutes following the second conflict. 

as the matched-control ('MC') observation. MC observations were paired to PC observations following four criteria: (1) they involved the same focal individual and its former opponent, (2) no aggression occurred between the focal subject and its former opponent during the $\mathrm{x}$ minutes preceding the start of the MC observation, (3) they occurred less than seven days apart and (4) the female was in the same reproductive state (pregnant, lactating, oestrous or cycling non-oestrous) (see Appendix 2 in Supplementary Materials for more details about the selection of MC observations). In order to gather enough MC observations that met these four selection criteria, it was necessary to accept MC observations that were collected at different times of day from the corresponding PC observation. However, we ensured that selecting MC observations randomly did not bias the data in any particular direction for time of day (see Figure S1). We then assessed whether the focal individual affiliated with its former opponent in the MC observation (no: 0; yes: 1).

We subsequently determined, for each PC-MC pair, whether it was 'attracted' (i.e., affiliation occurred earlier or exclusively in the PC observation), 'dispersed' (affiliation occurred earlier or exclusively in the MC observation) or 'neutral' (affiliation did not occur in either observation, or occurred at the same time). A Wilcoxon matched-pair signed-rank test that compared the proportion of attracted and dispersed pairs for each individual female was used to test for a signal of reconciliation. Only females involved in at least five aggressive acts (mean \pm SD: $7.9 \pm 2.5$ for the 5-min dataset) were included. We also calculated the corrected conciliatory tendency (CCT) for each focal female defined as 'the number of attracted minus dispersed pairs in which an individual is involved, divided by its total number of PC-MC pairs' (Veenema et al., 1994).

Using approaches and leaves occurring within 1m of the focal subject, we also calculated for each PC-MC pair the average time that the male and female spent in close 
proximity in the PC and MC observation. We tested whether opponents were in closer proximity in PC than in MC observations using a Wilcoxon matched-pair signed-rank test, as such a difference could bias results towards more affiliation in PC observations. Opponents spent the same amount of time within 1m in PC and MC observations (Table S2, except for the 5-min dataset), indicating that PC and MC observations were directly comparable for the 10, 15 and 20-min datasets.

\section{Method using baseline rate of affiliation}

We implemented a second method (adapted from the time-rule and rate methods described in Aureli et al., 1989; Cords, 1993; Judge, 1991; Kappeler \& van Schaik, 1992; Veenema et al., 1994), that uses baseline levels of affiliation among members of a dyad and compares multiple PC observations to multiple control observations. Using our large body of focal observations, we began by establishing the rate of affiliation between a given pair of individuals (1) in the $\mathrm{x}$ $(x=5,10,15$ and 20) minutes following aggression between them (i.e., the post-conflict samples) and (2) when no aggression occurred in the x preceding minutes (i.e., the baseline samples). This involved a three-step process. First, for each heterosexual dyad that exchanged at least one act of aggression, we identified all focal observations (i) that were conducted on both individuals in a given year and (ii) where the female was in a given reproductive state (non-oestrus, oestrus, pregnant, lactating). Second, we split these observations into two categories: the post-conflict sample, where we pooled all observations that followed a conflict between the dyad members, and the baseline sample, where we pooled all observations that were not preceded by a conflict. In some cases, PC observations were incomplete (e.g., because the focal individual went out of sight or another aggression occurred). We therefore retained only PC observations that lasted at least 3, 6, 9 and 12 min for the 5, 10, 15 and 20-min datasets, respectively (i.e., $\geq 60 \%$ of the observation time). For each baseline observation, we removed 
$\mathrm{x}$ minutes of observation at the start of the focal observation and after the focal individual went out of sight for a couple of minutes (in case an aggression occurred between the two members of the dyad as they were out of sight). Third, we tabulated the number of times that the two individuals affiliated in the respective post-conflict and baseline sample, as well as the total observation time of the corresponding sample, thus generating the rates of affiliation in each case.

We analysed the difference in the mean rate of affiliation between the post-conflict and baseline samples across male-female dyads using a generalised linear mixed-effect model (GLMM) with a Poisson error structure. The number of affiliations exchanged by each malefemale dyad was fitted as the response variable. The total observation time of the corresponding sample (post-conflict or baseline) was log-transformed and included as an offset variable to model a rate of affiliation. The fixed effects comprised the type of observation (post-conflict samples: 1 , baseline samples: 0 ). Random effects comprised the identity of the female, male, affiliations are more common after a conflict.

All GLMMs were run using the glmer function of the lme4 package (Bates, Maechler, Bolker, \& Walker, 2014) in R version 3.4.1 (R Core Team, 2017). The significance of the fixed factors was tested by computing their 95\% bootstrap confidence intervals (using confint.merMod) and checking that they did not cross zero. Their p-values were calculated by using the PBmodcomp function from the pbkrtest package (Halekoh \& Højsgaard, 2014), which compares a model with and without the variable using a parametric bootstrap method. To test for differences between all levels of multilevel categorical variables, we changed the reference category sequentially and refitted the model (Pinheiro \& Bates, 2000). 


\section{Reconciliation between males and pregnant/lactating females}

After validating the new method (see results), we then investigated in more detail patterns of reconciliation between males and non-cycling females (i.e., pregnant and lactating), especially in relation to their friendship status. Using the previously established dataset, we ran a GLMM with a Poisson error structure using the number of affiliations exchanged between male and female dyads as the response variable, but selecting only heterosexual dyads involving pregnant and lactating females. We chose the dataset looking at 15-min after aggression for this analysis, because the sample size was reasonably high and the strength of the reconciliation signal was maximal in this dataset (see Results). As above, the total observation time of the corresponding sample (post-conflict or baseline) was log-transformed and included as an offset variable to model a rate of affiliation. Random effects comprised the identity of the female, male, and dyad. Fixed effects included the social context, i.e., a categorical variable recording whether (i) the male and female of the dyad were friends and (ii) the observation was postconflict or not, with four levels: PC \& friend, baseline \& friend, PC \& non-friend, baseline \& non-friend. We created this variable to avoid fitting an interaction between two qualitative variables (here, the type of observation and the friendship status of the dyad), which are hard to estimate statistically and pose challenges for interpreting results. The reproductive state of the female of the dyad (pregnant or lactating), the relative rank of the female, and the relative rank of the male (averaged over the period of observation used to estimate the corresponding affiliation rate) were additionally entered as fixed effects.

RESULTS 
351 Consistent with our prediction that heterosexual dyads would exhibit reconciliation, males and females were more likely to affiliate after an aggression than by chance (Table 1, Figure 1a). The reconciliation signal was significant at 5, 10, 15 and $20 \mathrm{~min}$, and peaked at 20-min, where $37 \%$ of conflicts were reconciled. The downstream figures were nevertheless estimated from the 15 min dataset, which includes a relatively high rate of reconciliation (33\% of conflicts) alongside a larger number of conflicts ( $\mathrm{N}=126$ versus 75 in the 20 min dataset), thereby offering higher statistical resolution. The average duration between aggression and the first affiliative contact was $4.0 \pm 4.0 \mathrm{~min}$ (mean $\pm \mathrm{SD}$, calculated over 42 conflicts followed by affiliation in the 15 min dataset). Of these 42 reconciled conflicts, the first affiliation was initiated 22 times by the male (52\%) and 20 times by the female (48\%). The four most common first post-conflict affiliative acts used to reconcile were presenting (36\%), one or more grunts (19\%), a grooming initiation (14\%), and a copulation (12\%). Individual females differed highly in their tendency to reconcile with the opposite sex (Table 1, Figure 1b), with some subjects who never reconciled, and others who reconciled up to $60 \%$ of their conflicts - though this figure is based on a relatively low number of conflicts per individual (mean \pm SD:6.63 \pm 2.03 , min-max:5-12).

\section{Method using baseline rate of affiliation}

Male-female dyads were found to affiliate at higher rates in the PC samples than in the baseline samples, regardless of whether $5,10,15$ or 20 min of PC samples were selected (Table 2,

Figure 2). This is in accordance with the results of the PC-MC method, showing that this method is appropriate for investigating patterns of reconciliation.

\section{Reconciliation between males and pregnant/lactating females}

Friend dyads affiliated at much higher rates after a conflict than in baseline observations (rate of affiliation \pm SD in PC: $0.04 \pm 0.07$ time/min and in baseline: $0.01 \pm 0.01$ ), although with high 
levels of variation across dyads. In contrast, non-friend dyads affiliated at comparable rates across post-conflict and baseline observations (rate of affiliation \pm SD in PC: $0.00 \pm 0.01$ and in baseline: $0.00 \pm 0.00$ ) (Table 3, Figure 3). As predicted, friend dyads also affiliated significantly more than non-friend dyads after a conflict. Counter to our prediction that females would be the more frequent initiators of reconciliation, out of 32 aggressive events observed between friend dyads, 10 were reconciled, and the first affiliation was initiated by the male in half of these cases $(n=5)$. Out of 41 aggressive interactions observed between non-friend dyads, only one was reconciled (initiated by the female). Overall, these results indicate that reconciliation between pregnant/lactating females and males occurs only if they are friends. Unsurprisingly, we also found that friends affiliated more than non-friends across baseline observations. Female reproductive state (pregnant or lactating) and male and female rank did not influence dyadic rates of affiliation.

\section{DISCUSSION}

We validate a new methodological approach to study reconciliation patterns using long-term datasets, and implement it to test the VRH in a novel context, that of reconciliation between male and female chacma baboons. Our analyses indicate affiliative reunions occur following conflicts between adult heterosexual pairs. Further, we demonstrate that such reconciliation regularly occurs between males and pregnant/lactating females who are engaged in friendships (who also exchange higher baseline levels of affiliation) but is virtually absent among males and pregnant/lactating females who are not friends. Such 'friendships' are strong, stable associations that are mutually beneficial at both a proximate and ultimate level (see below), and evidently worthy of reconciling in the face of conflict. These findings thus lend further credence to the overall value of heterosexual bonds in this species, whose role is often 
overlooked in structuring the social organization of baboon societies (Archie et al., 2014; Baniel et al., 2016; Cheney et al., 2012).

According to the VRH, reconciliation should be present when any resulting damage to the relationship has important fitness consequences (de Waal \& Aureli, 1997; Kappeler \& van Schaik, 1992). In this case, the potential fitness costs of disrupted male-female relationships are manifold. For males, they may lead to a direct loss of mating opportunities and/or of grooming partners, which can be contingent on the quality of male-female social relationships (Smuts, 1985). Whenever they have sired their friend's offspring, males who lose their female friend also lose an opportunity to invest in their own descent (Buchan, Alberts, Silk, \& Altmann, 2003; Huchard et al., 2010; Moscovice et al., 2010). A disruption of the motherfather relationship may consequently weaken the father-offspring bond during weaning, which can in turn impair infant survival and nutritional benefits obtained through paternal care (Charpentier, Van Horn, Altmann, \& Alberts, 2008; Huchard et al., 2013). For females with infants, disrupted relationships to males may translate into a loss of paternal care, and notably to a higher infanticide risk (Buchan et al., 2003; Huchard et al., 2013; Palombit et al., 1997). Damaged relationships with males may also result in females losing males' protection, and potentially incurring subsequent harassment from dominant females and aggression from other resident males (Lemasson, Palombit, \& Jubin, 2008; Nguyen, Van Horn, Alberts, \& Altmann, 2009), and of associated costs such as injuries (Baniel et al., 2017) and increased risks of miscarriages (Zipple et al., 2017). Friendships with males also buffer females against elevated stress levels during periods of group instability, such as when a new male immigrates (e.g., Beehner, Bergman, Cheney, Seyfarth, \& Whitten, 2005). Considering these myriad fitness benefits, the presence of post-conflict conciliatory interactions between males and females underscores the adaptive value of repairing the adverse consequences of at least some conflicts in these relationships. 
towards females does not necessarily indicate commensurate asymmetry in who initiates reconciliation. In fact, contrary to expectations, the initiation of post-conflict affiliation in these male-female dyads exhibited near symmetry, inviting us to speculate that the motivation behind repairing these valuable relationships is not purely one-sided. Heterosexual friendships are characterized by a strong asymmetry in the maintenance of proximity among partners—-where only females actively contribute (Huchard et al., 2010; Lemasson et al., 2008; Palombit et al., 1997) — which has long raised questions over males' motivations for such bonds. The initiative of males in relationship-repair strategies like reconciliation provides a new form of evidence that males are indeed motivated to maintain relationships to female friends. This adds further nuance to the present study's support for the VRH, in that the fitness consequences of such relationships may be more jointly motivating than previously assumed. More generally, it sheds new light on how patterns of reconciliation can be revelatory for understanding shared investments in social bonds in ways that proximity measures alone do not capture.

In wild olive baboons, Castles and Whiten (1998b) found that conflicts increased stress for both victims and aggressors, as evidenced by elevated rates of self-directed behaviours in PC periods. Reconciliation served to reduce this stress, but only amongst individuals involved in bilateral conflicts in which both parties exchanged aggression. Unilateral victims of conflict, particularly in despotic species like chacma baboons, may be reluctant to approach recent aggressors. Nonetheless, females in our study did not appear constrained in the initiative to reconcile compared to their male aggressor counterparts, indicating that the benefits of initiating reconciliation might outweigh the risks of receiving renewed aggression. Nonetheless, the extent to which males and females are differentially stressed by these asymmetrical conflicts-and further whether reconciliation actually serves to reduce stress in 
both victims/aggressors and restore tolerance in those dyads-is an area that warrants further investigation.

An additional prospective line of research concerns the relative rates of reconciliation across different relationships and individuals. Notably, the rates of reconciliation reported here (nearly one third of all conflicts) are consistently higher than those reported by Silk and colleagues' (1996) research on female-female chacma baboons, who often grunt to reconcile with former opponents (13\% of all cases). In fact, whereas the likelihood of approaches and grunts increased following conflicts in Silk et al's (1996) study, other affiliative behaviours generally decreased. The discrepancy between these results and ours may be a consequence of the present study's inclusion of a wider repertoire of potential post-conflict behaviours. It could further be attributable to differences in the way conflict and PC data were extracted: whereas in their study it is unclear whether successive bouts of aggression were counted as one or more conflict(s), our study focused only on the most recent conflict in a series of aggressions. This may have contributed to Silk et al.'s (1996) finding that rates of aggression between former opponents were higher in PC than in MC samples, whereas our study design prevented us from observing such a contrast, as aggression rates between opponents in PC samples were set to 0 by construction. Acknowledging such differences is not to overlook the distinct possibility that male-female dyads indeed reconcile more frequently than do female-female dyads, particularly given the pronounced evolutionary stakes.

That some subjects in our study rarely reconciled, while others did so rather frequently, is an area that also warrants further study. Individual variation may reflect the variable quality of the relationships of different individuals (with higher reconcilers having more valuable bonds) or stable individual differences, as recently emphasized by work incorporating conflict management skills as a component of broader animal personality (Webb, Franks, Romero, Higgins, \& de Waal, 2014; Webb, Romero, Franks, \& de Waal, 2017; Webb \& Verbeek, 2016). 
Our results further revealed that even among friendship dyads there is considerable variation

in the tendency to reconcile, which is not simply explained by variation in male and female dominance ranks. It would be interesting to disentangle the causes and consequences of observed variations in reconciliation rates across dyads and individuals by determining whether having better social bonds leads to higher reconciliation, or, alternatively, having higher reconciliation tendencies facilitates better social bonds. In the first case, we would expect relationship quality to predict the likelihood of reconciliation independently of individual factors. In the second case, we would expect relationship quality and reconciliation tendency to be predicted by the same individual factors.

Finally, studies like this might further our understanding of heterosexual reconciliatory patterns across species, and in turn help to elucidate the nature of male-female associations across other social/mating systems. It would be especially interesting to consider where reconciliation is absent in this regard. Studies of cooperative breeders have found little evidence for reconciliation, even within the breeding pair for whom the relationship has clear fitness value for both partners (reviewed in Schaffner \& Caine, 2000). In red-bellied tamarins, for example, reconciliation is thought to be absent largely because conflicts of interest seldom escalate into overt aggression with the potential to damage relationships (Schaffner, Aureli, \& Caine, 2005, cf Peñate et al., 2009). The pair-bonded nature of most bird species, in which mates seldom fight, may also preclude the need for reconciliation (see Logan, Emery, \& Clayton, 2012; Seed, Clayton, \& Emery, 2007), though post-conflict affiliation occurs in valuable relationships outside of the pair bond (Fraser \& Bugnyar, 2011). Differences in avian and mammalian reconciliation behavior have been attributed not merely to the lower incidence of aggression in monogamous relationships, but to the fluidity of avian social systems which may facilitate post-conflict dispersal (Fraser \& Bugnyar, 2011; Seed et al., 2007). Overall, reconciliation may be most frequent in societies with low average kinship among group 
members like those of promiscuous mammals, where conflicts of interests are common and require individuals to develop complex strategies to manage differentiated and fitnessenhancing relationships with non-kin (Lukas \& Clutton-Brock, 2018).

502

\section{CONCLUSION}

504 Post-conflict interactions among heterosexual pairs have rarely been studied in wild promiscuous social systems, despite growing knowledge that males and females form longterm associations marked by clear fitness consequences for both partners. Our study reveals that male and female baboons engage in affiliative post-conflict reunions at higher rates than expected from baseline measures of affiliation-that is, they engage in reconciliation. The present research shows that reconciliation rates are high among friends and absent among nonfriends, and further reveals that males and females are equally likely to initiate reconciliation.

This sheds new light on the shared investment of heterosexual friends in their relationship, a picture which is more consistent with the mutual benefits obtained from such bonds.

\section{REFERENCES}

Alberts, S. C., \& Altmann, J. (1995). Balancing costs and opportunities: dispersal in male baboons. American Naturalist, 145(2), 279-306.

Altmann, J., \& Alberts, S. C. (2003). Variability in reproductive success viewed from a lifehistory perspective in baboons. American Journal of Human Biology, 15(3), 401-409.

Archie, E. A., Tung, J., Clark, M., Altmann, J., \& Alberts, S. C. (2014). Social affiliation matters: both same-sex and opposite-sex relationships predict survival in wild female baboons. Proceedings of the Royal Society B-Biological Sciences, 281, 20141261.

Arnold, K., Fraser, O. N., \& Aureli, F. (2010). Postconflict reconciliation. In C. J. Campbell, 

Perspective (pp. 608-625). Oxford, UK: Oxford University Press.

Aureli, F., van Schaik, C. P., \& van Hooff, J. A. R. A. M. (1989). Functional aspects of reconciliation among captive long-tailed macaques (Macaca fascicularis). American Journal of Primatology, 19, 39-51.

Baniel, A., Cowlishaw, G., \& Huchard, E. (2016). Stability and strength of male-female associations in a promiscuous primate society. Behavioral Ecology and Sociobiology, 70(5), 761-775.

Baniel, A., Cowlishaw, G., \& Huchard, E. (2017). Male violence and sexual intimidation in a wild primate society. Current Biology, 27(14), 2163-2168.

Bates, D., Maechler, M., Bolker, B., \& Walker, S. (2014). lme4: linear mixed-effects models using Eigen and S4. R package version 1.1-7. R Package Version 1.1-7.

Beehner, J. C., Bergman, T. J., Cheney, D. L., Seyfarth, R. M., \& Whitten, P. L. (2005). The effect of new alpha males on female stress in free-ranging baboons. Animal Behaviour, 69(5), 1211-1221.

Bshary, R., \& Würth, M. (2001). Cleaner fish Labroides dimidiatus manipulate client reef fish by providing tactile stimulation. Proceedings of the Royal Society B: Biological Sciences, 268(1475), 1495-1501.

Buchan, J. C., Alberts, S. C., Silk, J. B., \& Altmann, J. (2003). True paternal care in a multimale primate society. Nature, 425(6954), 179-181.

Castles, D. L., \& Whiten, A. (1998). Post-conflict behaviour of wild olive baboons. II. Stress and self-directed behavior. Ethology, 104(2), 148-160.

Charpentier, M. J. E., Van Horn, R. C., Altmann, J., \& Alberts, S. C. (2008). Paternal effects on offspring fitness in a multimale primate society. Proceedings of the National Academy of Sciences, 105, 1988-1992.

Cheney, D. L., Seyfarth, R. M., \& Silk, J. B. (1995). The role of grunts in reconciling 
opponents and facilitating interactions among adult female baboons. Animal Behaviour, 50, 249-257.

551

Cheney, D. L., Silk, J. B., \& Seyfarth, R. M. (2012). Evidence for intrasexual selection in wild female baboons. Animal Behaviour, 84(1), 21-27.

Cools, A. K. A., Van Hout, A. J. M., \& Nelissen, M. H. J. (2008). Canine reconciliation and third-party-initiated postconflict affiliation: Do peacemaking social mechanisms in dogs rival those of higher primates? Ethology, 114, 53-63.

Cooper, M. A., Bernstein, I. S., \& Hemelrijk, C. K. (2005). Reconciliation and relationship quality in Assamese macaques (Macaca assamensis). American Journal of Primatology, 65(3), 269-282.

Cordoni, G., \& Norscia, I. (2014). Peace-Making in Marsupials: The first study in the rednecked wallaby (Macropus rufogriseus). PLoS ONE, 9(1), e86859.

Cordoni, G., \& Palagi, E. (2008). Reconciliation in wolves (Canis lupus): New evidence for a comparative perspective. Ethology, 114(3), 298-308.

Cords, M. (1993). On operationally defining reconciliation. American Journal of Primatology, 29(4), 255-267.

Cords, M., \& Thurnheer, S. (1993). Reconciliation with valuable partners by long-tailed macaques. Ethology, 93(4), 315-325.

Cowlishaw, G. (1997). Refuge use and predation risk in a desert baboon population. Animal Behaviour, 54(2), 241-253.

Cozzi, A., Sighieri, C., Gazzano, A., Nicol, C. J., \& Baragli, P. (2010). Post-conflict friendly reunion in a permanent group of horses (Equus caballus). Behavioural Processes, 85(2), 185-190. Quarterly Review of Biology, 61(4), 459-479. 
de Waal, F. B. M., \& Aureli, F. (1997). Conflict resolution and distress alleviation in monkeys and apes. In C. S. Carter, B. Kirkpatric, \& I. Lenderhendler (Eds.), The Integrative Neurobiology of Affiliation (Vol. 807, pp. 317-328). New York: Annals of the New York Academy of Sciences.

de Waal, F. B. M., \& van Roosmalen, A. (1979). Reconciliation and consolation among chimpanzees. Behavioral Ecology and Sociobiology, 5(1), 55-66.

de Waal, F. B. M., \& Yoshihara, D. (1983). Reconciliation and redirected affection in Rhesus monkeys. Behaviour, 85(3/4), 224-241.

Fraser, O. N., \& Bugnyar, T. (2011). Ravens reconcile after aggressive conflicts with valuable partners. PLOS ONE, 6(3), e18118.

Fraser, O. N., Stahl, D., \& Aureli, F. (2010). The function and determinants of reconciliation in Pan troglodytes. International Journal of Primatology, 31(1), 39-57.

Halekoh, U., \& Højsgaard, S. (2014). A Kenward-Roger approximation and parametric bootstrap methods for tests in linear mixed models - The R package pbkrtest. Journal of Statistical Software, 59(9), 1-30.

Huchard, E., Alvergne, A., Fejan, D., Knapp, L. A., Cowlishaw, G., \& Raymond, M. (2010). More than friends? Behavioural and genetic aspects of heterosexual associations in wild chacma baboons. Behavioral Ecology and Sociobiology, 64, 769-781.

Huchard, E., Charpentier, M. J., Marshall, H., King, A. J., Knapp, L. A., \& Cowlishaw, G. (2013). Paternal effects on access to resources in a promiscuous primate society. Behavioral Ecology, 24(1), 229-236.

Judge, P. G. (1991). Dyadic and triadic reconciliation in pigtail macaques (Macaca nemestrina). American Journal of Primatology, 23, 224-237.

Kappeler, P. M. (1993). Reconciliation and post-conflict behaviour in ringtailed lemurs, Lemur catta and redfronted lemurs, Eulemur fulvus rufus. Animal Behaviour, 45, 901- 
Kappeler, P. M., \& van Schaik, C. P. (1992). Methodological and evolutionary aspects of reconciliation among primates. Ethology, 92(2), 51-69.

602

603

604

605

606

607

608

609

610

611

612

613

614

615

616

617

618

619

620

621

622

623

Koski, S. E., Koops, K., \& Sterck, E.H.M. (2007). Reconciliation, relationship quality, and postconflict anxiety: Testing the integrated hypothesis. American Journal of Primatology, 69, 158-172.

Kutsukake, N., \& Castles, D. L. (2004). Reconciliation and post-conflict third-party affiliation among wild chimpanzees in the Mahale Mountains, Tanzania. Primates, 45(3), 157-165.

Lemasson, A., Palombit, R. A., \& Jubin, R. (2008). Friendships between males and lactating females in a free-ranging group of olive baboons (Papio hamadryas anubis): Evidence from playback experiments. Behavioral Ecology and Sociobiology, 62, 1027-1035.

Logan, C. J., Emery, N. J., \& Clayton, N. S. (2012). Alternative behavioral measures of postconflict affiliation. Behavioral Ecology, 24(1), 98-112.

Lukas, D., \& Clutton-Brock, T. (2018). Social complexity and kinship in animal societies. Ecology Letters, 21(8), 1129-1134.

McDonald, D. B. (2007). Predicting fate from early connectivity in a social network. Proceedings of the National Academy of Sciences, 104(26), 10910-10914.

Moscovice, L. R., Di Fiore, A., Crockford, C., Kitchen, D. M., Wittig, R., Seyfarth, R. M., \& Cheney, D. L. (2010). Hedging their bets? Male and female chacma baboons form friendships based on likelihood of paternity. Animal Behaviour, 79(5), 1007-1015.

Nguyen, N., Van Horn, R. C., Alberts, S. C., \& Altmann, J. (2009). “Friendships” between new mothers and adult males: Adaptive benefits and determinants in wild baboons (Papio cynocephalus). Behavioral Ecology and Sociobiology, 63(9), 1331-1344.

Palombit, R. A., Cheney, D. L., \& Seyfarth, R. M. (2001). Female-female competition for 
male “friends” in wild chacma baboons, Papio cynocephalus ursinus. Animal Behaviour, 61, 1159-1171.

Palombit, R. A., Seyfarth, R. M., \& Cheney, D. L. (1997). The adaptive value of “friendships” to female baboons: experimental and observational evidence. Animal Behaviour, 54(3), 599-614.

Peñate, L., Peláez, F., \& Sánchez, S. (2009). Reconciliation in captive cotton-top tamarins (Saguinus oedipus), a cooperative breeding primate. American Journal of Primatology, 71(11), 895-900.

Pinheiro, J. C., \& Bates, D. M. (2000). Mixed-Effects Models in S and S-plus. (J. Chambers, W. Eddy, W. Härdle, S. Sheather, \& L. Tierney, Eds.). New York: Springer.

R Core Team. (2017). R: A language and environment for statistical computing. In $R$ Foundation for Statistical Computing. Vienna, Austria.

Romero, T., \& Aureli, F. (2017). Conflict resolution. In J. Call (Ed.), APA Handbook of Comparative Psychology: Basic Concepts, Methods, Neural Substrate, and Behavior (Vol. 1, pp. 1-9). Washington, DC: American Psychological Association.

Romero, T., Colmenares, F., \& Aureli, F. (2008). Postconflict affiliation of aggressors in Papio hamadryas. International Journal of Primatology, 29(6), 1591-1606.

Schaffner, C. M., Aureli, F., \& Caine, N. G. (2005). Following the rules: Why small groups of tamarins do not reconcile conflicts. Folia Primatologica, 76, 67-76.

Schaffner, C. M., \& Caine, N. G. (2000). The peacefulness of cooperatively breeding primates. In F. Aureli \& F. B. M. de Waal (Eds.), Natural Conflict Resolution (pp. 155169). Berkeley, CA: University of California Press.

Schino, G. (1998). Reconciliation in domestic goats. Behaviour, 135, 343-356.

Schino, G., Rosati, L., \& Aureli, F. (1998). Intragroup variation in conciliatory tendencies in captive Japanese macaques. Behaviour, 135(7), 897-912. 
Seed, A. M., Clayton, N. S., \& Emery, N. J. (2007). Postconflict third-party affiliation in rooks, Corvus frugilegus. Current Biology, 17(2), 152-158.

Silk, J. B., Beehner, J. C., Bergman, T. J., Crockford, C., Engh, A. L., Moscovice, L. R., ... Cheney, D. L. (2010). Strong and consistent social bonds enhance the longevity of female baboons. Current Biology, 20(15), 1359-1361.

Silk, J. B., Cheney, D. L., \& Seyfarth, R. M. (1996). The form and function of post-conflict interactions between female baboons. Animal Behaviour, 52, 259-268.

Smuts, B. (1985). Sex and Friendship in Baboons. Hawthorne, NY: Aldine Publishing.

Stanton, M. A., \& Mann, J. (2012). Early social networks predict survival in wild bottlenose dolphins. PLoS ONE, 7(10), 1-6.

Veenema, H. C. (2000). Methodological progress in post-conflict research. In F. Aureli \& F. B. M. de Waal (Eds.), Natural Conflict Resolution (pp. 21-23). Berkeley, CA: University of California Press.

Veenema, H. C., Das, M., \& Aureli, F. (1994). Methodological improvements for the study of reconciliation. Behavioural Processes, 31, 29-38.

Wahaj, S. A., Guse, K. R., \& Holekamp, K. E. (2001). Reconciliation in the spotted hyena (Crocuta crocuta). Ethology, 107(12), 1057-1074.

Watts, D. P. (1995). Post-conflict social events in wild mountain gorillas I. Social interactions between opponents. Ethology, 100(2), 139-157.

Watts, D. P. (2006). Conflict resolution in chimpanzees and the valuable-relationships hypothesis. International Journal of Primatology, 27(5), 1337-1364.

Weaver, A. (2003). Conflict and reconciliation in captive bottlenose dolphins, Tursiops truncatus. Marine Mammal Science, 19(4), 836-846.

Webb, C. E., Franks, B., Romero, T., Higgins, E. T., \& de Waal, F. B. M. (2014). Individual differences in chimpanzee reconciliation relate to social switching behaviour. Animal 
Webb, C. E., Romero, T., Franks, B., \& de Waal, F. B. M. (2017). Long-term consistency in chimpanzee consolation behaviour reflects empathetic personalities. Nature Communications, 8(292), 1-8.

Webb, C. E., \& Verbeek, P. (2016). Individual differences in aggressive and peaceful behaviour: New insights and future directions. Behaviour, 153, 1139-1169.

Wittig, R. M., \& Boesch, C. (2003). The choice of post-conflict interactions in wild chimpanzees (Pan troglodytes). Behaviour, 140, 1527-1559.

Wittig, R. M., Crockford, C., Wikberg, E., Seyfarth, R. M., \& Cheney, D. L. (2007). Kinmediated reconciliation substitutes for direct reconciliation in female baboons. Proceedings of the Royal Society B: Biological Sciences, 274(1613), 1109-1115.

Yee, J. R., Cavigelli, S. A., Delgado, B., \& McClintock, M. K. (2008). Reciprocal affiliation among adolescent rats during a mild group stressor predicts mammary tumors and lifespan. Psychosomatic Medicine, 70(9), 1050-1059.

Zipple, M. N., Grady, J. H., Gordon, J. B., Chow, L. D., Archie, E. A., Altmann, J., \& Alberts, S. C. (2017). Conditional fetal and infant killing by male baboons. Proceeding of the Royal Society of London B, 284, 20162561.

691 
Ethical Note. Research procedures were approved by the Ethics Committee of the Zoological Society of London and the Ministry of Environment and Tourism of Namibia (permit numbers 886/2005, 1039/2006, 1786/2013, and 1892/2014), and adhered to the ASAB/ABS Guidelines for the Treatment of Animals in Behavioural Research and Teaching. 
Acknowledgements. We are grateful to the Tsaobis Baboon Project volunteers (2005-06 and 2013-14), the Tsaobis beneficiaries for permission to work at Tsaobis, the Gobabeb Research and Training Centre for affiliation, and the Snyman and Wittreich families for permission to work on their land. Thank you to Alexandre Courtiol for his useful advice on the statistical analyses. This paper is a publication of the ZSL Institute of Zoology's Tsaobis Baboon Project. C.E.W. was supported by a Fyssen Foundation postdoctoral fellowship and A.B. was supported by the Agence Nationale de la Recherche Labex IAST. Contribution ISEM 2019-002. 
994

Table 1. Results of the post-conflict matched-control method, for four different time periods. PC: post-conflict observations, MC: matchedcontrol observations. Significant p-values are highlighted in bold.

\begin{tabular}{llllllllll}
\multicolumn{1}{l}{$\begin{array}{l}\text { Mean } \\
\text { percentage of } \\
\text { attracted } \\
\text { pairs } \pm \text { SD }\end{array}$} & $\begin{array}{l}\text { Mean } \\
\text { percentage of } \\
\text { dispersed } \\
\text { pairs } \pm \text { SD }\end{array}$ & $\begin{array}{l}\text { Sample } \\
\text { size }^{\mathrm{a}}\end{array}$ & $\begin{array}{l}\text { No. } \\
\text { females/males }\end{array}$ & $V^{\mathrm{b}}$ & P-value $^{\mathrm{b}}$ & $\begin{array}{l}\text { No. (\%) PC } \\
\text { with affil }^{\mathrm{c}}\end{array}$ & $\begin{array}{l}\text { No.(\%) MC } \\
\text { with affil }^{\mathrm{d}}\end{array}$ & $\begin{array}{l}\text { Mean CCT } \\
\pm \text { SD }\end{array}$ \\
\hline 5min & $18.8 \pm 17.3$ & $7.8 \pm 8.3$ & 181 & $23 / 31$ & 107 & $\mathbf{0 . 0 0 8}$ & $39(21.5)$ & $20(11.0)$ & $11.0 \pm 18.0$ \\
$10 \mathrm{~min}$ & $23.4 \pm 18.3$ & $10.5 \pm 12.0$ & 152 & $22 / 30$ & 161 & $\mathbf{0 . 0 3 8}$ & $42(27.6)$ & $23(15.1)$ & $12.9 \pm 24.0$ \\
$15 \mathrm{~min}$ & $30.5 \pm 19.3$ & $12.1 \pm 14.1$ & 126 & $19 / 27$ & 107 & $\mathbf{0 . 0 0 8}$ & $42(33.3)$ & $29(23.0)$ & $18.5 \pm 23.2$ \\
$20 \mathrm{~min}$ & $35.2 \pm 19.8$ & $11.7 \pm 12.7$ & 75 & $12 / 24$ & 72 & $\mathbf{0 . 0 1 1}$ & $28(37.3)$ & $16(21.3)$ & $23.5 \pm 21.1$ \\
\hline
\end{tabular}

${ }^{\text {a }}$ Number of PC-MC pairs (=aggression events) available for the test.

b Statistic of a Wilcoxon matched-pairs signed-rank test that compares the difference between the proportion of attracted and dispersed pairs.

${ }^{\mathrm{c}}$ Number of PC observations including an affiliation between former opponents.

${ }^{\mathrm{d}}$ Number of MC observations including an affiliation between former opponents. 
70

04

Table 2. Results of the baseline affiliation method, for four different time periods. PC: post-conflict observations. We present the estimate and significance of the variable "Type of observation" (PC versus baseline samples) for the four GLMMS corresponding to the four different time periods (5, 10, 15 and 20 min). GLMMs were performed controlling for male, female and dyad identity. The 95\% confidence intervals and pvalues of statistically significant results are highlighted in bold.

\begin{tabular}{|c|c|c|c|c|c|c|c|c|c|}
\hline & $\begin{array}{l}\text { Rate of } \\
\text { affiliation in } \\
\mathrm{PC} \pm S \mathrm{~S}^{\mathrm{a}}\end{array}$ & $\begin{array}{l}\text { Rate of } \\
\text { affiliation in } \\
\text { baseline } \pm S D^{b}\end{array}$ & $\begin{array}{l}\text { No. } \\
\text { dyads }\end{array}$ & $\begin{array}{l}\text { No. } \\
\text { aggression }^{\mathrm{c}}\end{array}$ & Estimate & $\mathrm{SE}$ & $\begin{array}{c}95 \% \\
\text { confidence } \\
\text { interval }\end{array}$ & LRT & P-value \\
\hline $5 \mathrm{~min}$ & $0.04 \pm 0.09$ & $0.01 \pm 0.02$ & 163 & 256 & 1.23 & 0.16 & {$[0.90 ; 1.50]$} & 65.80 & 0.002 \\
\hline $10 \mathrm{~min}$ & $0.04 \pm 0.07$ & $0.01 \pm 0.02$ & 151 & 223 & 1.15 & 0.10 & {$[0.90 ; 1.37]$} & 88.48 & 0.002 \\
\hline $15 \mathrm{~min}$ & $0.03 \pm 0.06$ & $0.01 \pm 0.02$ & 146 & 210 & 1.11 & 0.09 & {$[0.89 ; 1.29]$} & 107.51 & 0.002 \\
\hline $20 \mathrm{~min}$ & $0.04 \pm 0.06$ & $0.01 \pm 0.02$ & 136 & 191 & 1.11 & 0.09 & {$[0.90 ; 1.27]$} & 123.30 & 0.002 \\
\hline
\end{tabular}

\footnotetext{
a The rate of affiliation in PC is calculated as the total number of affinitive interactions observed in PC divided by the total time of PC observations ${ }^{b}$ The baseline rate of affiliation is calculated as the total number of affinitive interactions observed in baseline divided by the total time of baseline observations

c Total number of PC observations.
} 
Table 3. Patterns of reconciliation between pregnant/lactating females and males. PC: post-conflict observations. Parameters and tests are

based on 31 females, 22 males, and 52 dyads (including 29 with a pregnant female and 23 with a lactating female). There were 18 friend dyads, and 73 events of aggression (mean \pm SD aggression observed per dyad: 1.4 \pm 0.8 ). Females have on average $20.0 \pm 11.3$ min of observation in PC and 867.0 \pm 284.9 min of observation in baseline. The GLMM was performed controlling for male, female and dyad identity. P-values are used to test for the significance of each variable, while the 95\% confidence intervals are used to test for the significance of each level of the qualitative variables. The confidence intervals and p-values of statistically significant results are highlighted in bold.

\begin{tabular}{|c|c|c|c|c|c|c|c|}
\hline $\begin{array}{l}\text { Response } \\
\text { variable }\end{array}$ & Fixed factor & Levels & Estimate & SE & $\begin{array}{c}95 \% \\
\text { confidence } \\
\text { interval } \\
\end{array}$ & LRT & P-value \\
\hline \multirow{7}{*}{$\begin{array}{l}\text { Number of } \\
\text { affiliations } \\
\text { exchanged } \\
\text { between } \\
\text { male-female } \\
\text { dyads }^{\text {a }}\end{array}$} & \multirow[t]{4}{*}{ Type of observation } & PC friend (ref: baseline friend) & 1.00 & 0.27 & {$[0.43 ; 1.42]$} & 31.67 & 0.002 \\
\hline & & PC non-friend (ref: baseline non-friend) & 0.53 & 0.72 & {$[-10.71 ; 1.54]$} & & \\
\hline & & PC friend (ref: PC non-friend) & 2.62 & 0.86 & {$[1.21 ; 12.86]$} & & \\
\hline & & Baseline friend (ref: baseline non-friend) & 2.15 & 0.44 & {$[1.24 ; 3.15]$} & & \\
\hline & Reproductive state $^{\mathrm{b}}$ & Pregnant & 0.20 & 0.39 & {$[-0.53 ; 0.96]$} & 0.27 & 0.634 \\
\hline & Female rank & & 0.85 & 0.61 & {$[-0.44 ; 2.20]$} & 1.59 & 0.252 \\
\hline & Male rank & & -0.43 & 0.81 & {$[-2.51 ; 1.21]$} & 0.27 & 0.643 \\
\hline
\end{tabular}

${ }^{a}$ The duration (min) of observation of each dyad was fitted as an offset fixed factor, to control for variation in observation time across dyads.

${ }^{\mathrm{b}}$ Reference category: lactating 
Figure 1. Patterns of reconciliation between males and females, as assessed by the post-conflict matched-control method. (a) Percentage of observations containing at least one affiliation in the post-conflict (black bar) and matched-control (grey bar) sample. (b) Corrected conciliatory tendency (CCT) for each individual female ( $\mathrm{N}=19$ females, including four with a CCT of zero that are invisible for the 15-min dataset. The average CCT across females is indicated by the dotted line.

(a)

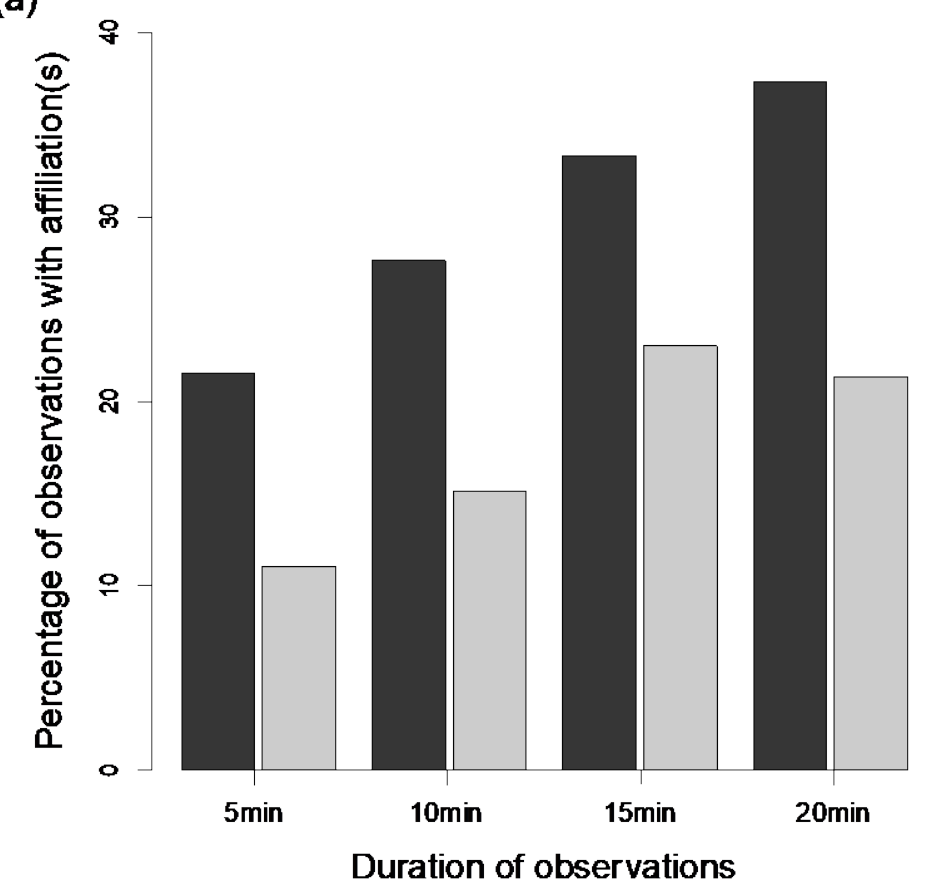

(b)

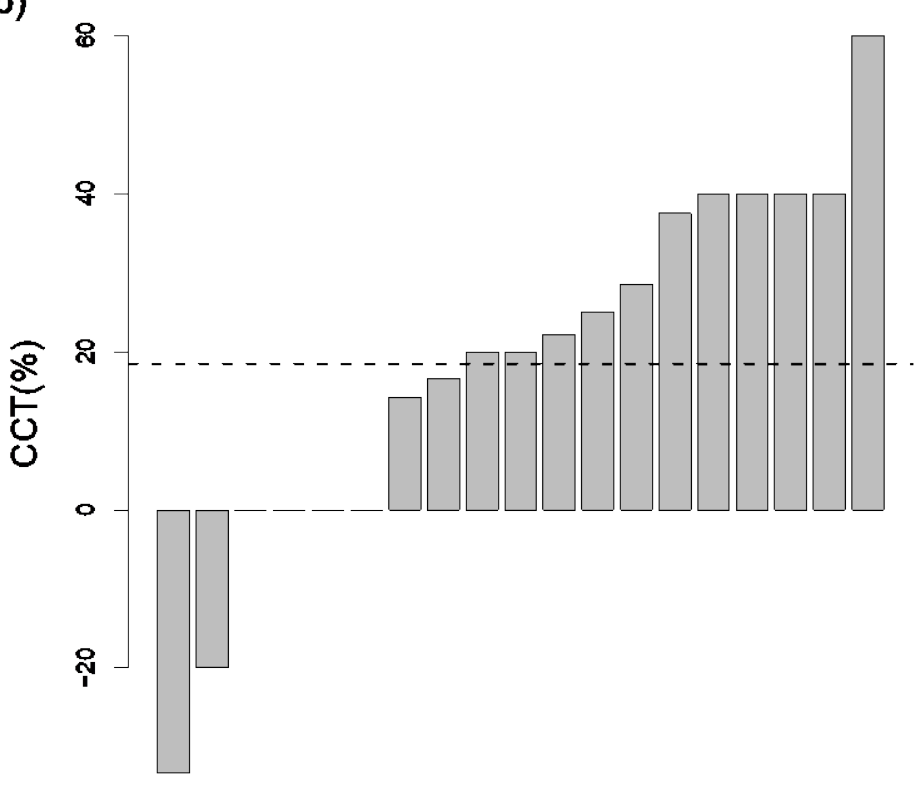

Female subjects 
729 affiliation method. Mean rate of affiliation in post-conflict (PC) versus baseline samples 730 across male-female dyads. Data are shown for 15-min observations. Black bars represent the 731 standard error and grey dots represent the raw mean of each dyad.

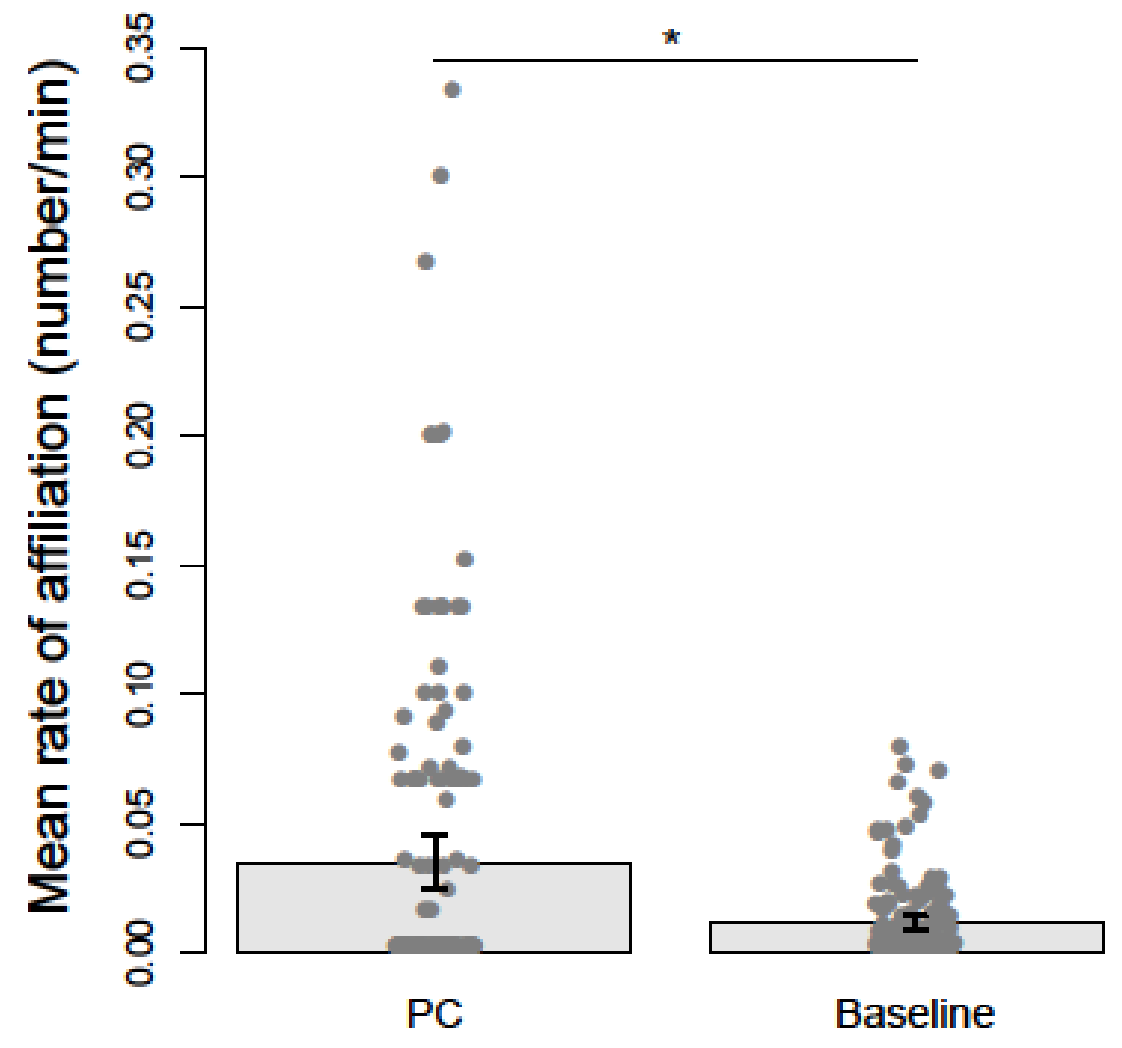



assessed by the baseline affiliation method. Mean rate of affiliation between pregnant/lactating female and a male, according to the context (PC versus baseline) and to their

737 friendship status (friend/non-friend). Data are shown for 15-min observations. Black bars 738 represent the standard error and grey dots represent the raw mean of each dyad. The significance of the difference between all levels of categorical variables is evaluated by changing contrasts in GLMMs. $* P<0.05$.

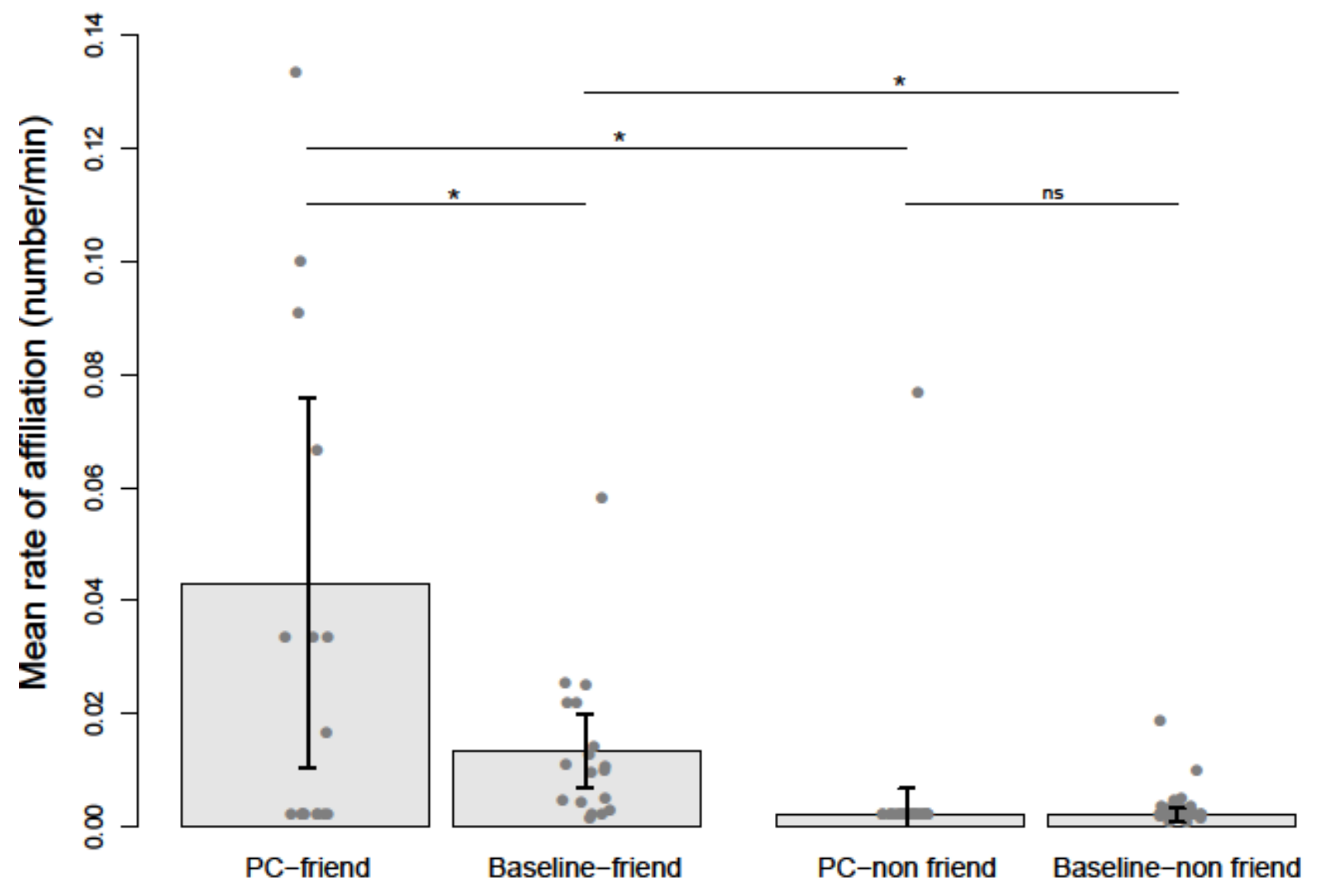

